\title{
RESEARCH
}

Open Access

\section{Cardiovascular disease in COVID-19: a systematic review and meta-analysis of 10,898 patients and proposal of a triage risk stratification tool}

Sara Momtazmanesh ${ }^{1,2 \dagger}$, Parnian Shobeiri ${ }^{1,2+}$, Sara Hanaei ${ }^{1,2,3}$, Hani Mahmoud-Elsayed ${ }^{4}$, Bharat Dalvi ${ }^{5}$ and Elaheh Malakan $\operatorname{Rad}^{1,6^{*}}$ (D)

\begin{abstract}
Background: Coronavirus disease 2019 (COVID-19) pandemic has drastically affected global health. Despite several studies, there is yet a dearth of data regarding the mechanisms of cardiac injury, clinical presentation, risk factors, and treatment of COVID-19-associated cardiovascular disease. This systematic review and meta-analysis is aimed at defining the clinical, electrocardiographic, and pathologic spectrum of cardiovascular disease (CVD), frequency of elevated cardiac and inflammatory biomarkers, and their frequency and relationship with severity of the disease and mortality in COVID-19 patients and to develop a triage risk stratification tool (TRST) that can serve as a guide for the timely recognition of the high-risk patients and mechanism-targeted therapy. We conducted an online search in databases of PubMed and Embase to identify relevant studies. Data selection was in concordance with PRISMA guidelines. Results were presented as pooled frequencies, odds ratio, standardized mean difference (SMD), and forest and funnel plots.
\end{abstract}

Results: We gathered a total of 54 studies and included 35 of them in our meta-analysis. Acute cardiac injury occurred in more than $25 \%$ of cases, mortality was 20 times higher, and admission to intensive care unit increased by 13.5 times. Hypertension was the most common pre-existing comorbidity with a frequency of $29.2 \%$, followed by diabetes mellitus (13.5\%). The deceased group of patients had higher cardiac and inflammatory biomarkers, with statistically significant SMD, compared with survivors. Pediatric patients were predominantly mildly affected. However, less frequently, the presentation was very similar to Kawasaki disease or Kawasaki shock syndrome. This latter presentation hass been called as multisystem inflammatory syndrome in children (MIS-C).

Conclusions: There is a wide spectrum of cardiac involvement in COVID-19 patients, and hence a Triage Risk Stratification Tool can serve as a guide for the timely recognition of the high-risk patients and mechanism-targeted therapy.

Keywords: COVID-19, Cardiovascular disease, Troponin, Interleukin-6, Hypertension

\footnotetext{
* Correspondence: erad@tums.ac.ir

${ }^{\dagger}$ Sara Momtazmanesh and Parnian Shobeiri contributed equally as the first authors.

'Tehran University of Medical Sciences, Tehran, Iran

${ }^{6}$ Department of Pediatric Cardiology, Children's Medical Center (Pediatric

Center of Excellence), Tehran University of Medical Sciences, Tehran, Iran

Full list of author information is available at the end of the article
}

\section{Springer Open}

(๑) The Author(s). 2020 Open Access This article is licensed under a Creative Commons Attribution 4.0 International License, which permits use, sharing, adaptation, distribution and reproduction in any medium or format, as long as you give appropriate credit to the original author(s) and the source, provide a link to the Creative Commons licence, and indicate if changes were made. The images or other third party material in this article are included in the article's Creative Commons licence, unless indicated otherwise in a credit line to the material. If material is not included in the article's Creative Commons licence and your intended use is not permitted by statutory regulation or exceeds the permitted use, you will need to obtain permission directly from the copyright holder. To view a copy of this licence, visit http://creativecommons.org/licenses/by/4.0/. 


\section{Background}

Coronavirus disease 2019 (COVID-19) pandemic has drastically affected the global health and as of 15th May 2020 , resulted in 4,248,389 million confirmed cases and a death toll of 294,046 worldwide [1].

This disease has presented with a heterogeneous clinical course, ranging from asymptomatic carrier state to a lethal outcome with multi-organ failure and with a wide variety of case fatality rates ranging from 0.7 to $67 \%$ [2-4]. Although the respiratory tract is the most commonly involved organ system in this disease, other organs and particularly the heart are also affected with a negative impact on outcome [5]. Furthermore, pre-existing cardiovascular disease (CVD) can affect severity and mortality of these patients. Despite myriads of studies investigating cardiovascular diseases in patients with COVID19, there are still numerous unanswered questions, most importantly a triage risk stratification tool (TRST) that allows timely recognition of high-risk patients and well-timed delivery of risk-levelappropriate, patient-tailored, and pathophysiologicaltargeted treatment [6].

The aims of this systematic review and meta-analyses were (1) to calculate pooled frequency of newly developed and pre-existing CVD, hypertension, diabetes mellitus, cardiac symptoms as the initial presentations of COVID-19, elevation of cardiac and inflammatory biomarkers, acute hepatic, and renal injury; (2) to investigate association of newly developed and pre-existing CVD (including any acquired cardiac disease, encompassing ischemic and non-ischemic cardiomyopathies, or congenital heart disease) hypertension, and elevated cardiac and inflammatory biomarkers with severity of the disease and mortality; (3) to define the clinical spectrum and mechanisms of the newly developed cardiovascular diseases in the pediatric and adult population, the spectrum of newly developed arrhythmias and electrocardiographic changes and the pathologic findings of cardiac autopsies; and (4) to propose a TRST for timely detection and appropriate pathophysiologically targeted treatment of high-risk COVID-19 patients with associated CVD.

\section{Methods}

\section{Literature search and selection criteria}

We conducted an online search in databases of PubMed and Embase on 21st April 2020 to identify relevant studies. The search terms included "COVID-19," and "cardiovascular diseases," and other relevant or equivalent terms. We provided our search strategy in Supplementary Material 1 (S1). To retrieve additional eligible studies, we also traced the reference list of the retrieved papers and relevant reviews.
Studies were included if (1) they had reported associated cardiovascular diseases in COVID-19 patients, (2) assessed levels of cardiac biomarkers in COVID-19 patients, and (3) were original peer-reviewed studies (except for one study that we used in our qualitative analysis and was retrieved from MedRxiv) [7]. We did not apply any limitation on language or publication date. Studies were included in our quantitative analysis if they had a sample size of equal to or larger than ten. The rest of the articles, including case reports, case series, and studies investigating pathological features of the heart tissue, were assessed in the qualitative analysis. We excluded review articles.

Data selection was in concordance with the Preferred Reporting Items for Systematic Reviews and MetaAnalyses (PRISMA) guidelines [1]. Two authors (SM and PS) independently assessed the eligibility of the retrieved references. In case of disagreement, EMR made the final decision.

\section{Data extraction}

Three reviewers (SM, PS, and EMR) extracted (1) characteristics of the sample (age, gender, previous cardiovascular comorbidities, diabetes, and hypertension); (2) incidence of cardiovascular diseases; (3) levels of cardiac biomarkers, including troponins, N-terminal-pro B-type natriuretic peptide (NT-pro $\mathrm{BNP}$ ), myoglobin, creatine kinase $(\mathrm{CK})$, creatine kinase-MB (CK-MB), and lactate dehydrogenase (LDH) and inflammatory biomarkers including D-dimer, C-reactive protein (CRP), erythrocyte sedimentation rate (ESR), ferritin, interleukin-6 (IL-6), and tumor necrosis factor-alpha (TNF- $\alpha$ ); and (4) frequency of acute hepatic injury and acute kidney damage.

\section{Risk of bias assessment}

To critically appraise the included studies, we implemented the Newcastle-Ottawa scale (NOS) [8]. The possible scores of this scale range from 0 to 9 . Studies with a score of seven to nine, four to six, and zero to three were classified as studies with low, moderate, and high risk of bias, respectively.

\section{Statistical analysis}

We used OpenMeta Analyst [9] version 1.15.14 and RevMan version 5.3 [10]. Using forest plots, we illustrated the results of the analyses. We used funnel plots to illustrate the publication bias. The odds ratio (OR) were calculated to compare frequencies of acute cardiac injury, hypertension, and pre-existing cardiovascular diseases, between the "deceased" and the "recovered" patients and also between patients with "severe" and "non-severe" manifestations. We used standardized mean difference (SMD) to compare levels of cardiac troponin, CK, NTpro BNP, myoglobin, LDH, CRP, ESR, ferritin, IL-6, and 
LDH between the "deceased" and "recovered" patients and levels of CRP, LDH, CK, and CK-MB between the "severe" and "non-severe" cases.

We used the $I^{2}$ index to assess heterogeneity between studies. The $I^{2}$-indices of $0-25 \%, 26-75 \%$, and $75-100 \%$ represented low, moderate, and high degrees of heterogeneity, respectively [11]. We utilized fixed effects models if the results were homogeneous $(I<50 \%$ and $P>0.05)$ and random effect models if these results were heterogeneous $(I \geq 50 \%$ or $P \leq$ 0.05) [12].

To convert median and inter-quartile range (IQR) to mean and standard deviation (SD), we used statistical methods suggested by Luo et al. [13] and Wan et al. [14]. For one study which did not report the first and third quartiles of its data, we assumed the mean equal to the median and the standard deviation (SD) equal to IQR divided by 2 [6].

Our analysis of the comparison of patients with severe to those with non-severe COVID-19 included two types of categorization, namely "ICU" versus "non-ICU" groups and "severe" (defined as respiratory rate $\geq 30$ times/min, oxygen saturation at resting state $\leq 93 \%$, partial pressure of arterial oxygen to fraction of inspired oxygen ratio <300) versus "non-severe" (presented as without pneumonia or with mild pneumonia) categories. We also calculated the overall effect of each parameter on both groups (severe or ICU group and non-severe or non-ICU group) as a whole. In the series of studies with "ICU" versus "non-ICU" groups, we did not include the study performed by Du et al. [15], since they had clearly stated that all of their patients had an indication for ICU admission, but they could not admit them into ICU just because of a shortage of resources. Regarding study of Han et al. in which they had classified their patients into three subgroups as mild, severe, and critical, we merged the severe and critical groups. Additionally, we did not include Wan et al.'s [16] study in our subgroup analysis comparing acute cardiac injury in patients with severe and non-severe disease because their definition of acute cardiac injury was not precisely defined.

In the pooled frequency analysis of patients with higher levels of CRP, ESR, ferritin, IL-6, NT-pro BNP, D-dimer, LDH, cardiac troponins, myoglobin, CK, and CK-MB, we only included the studies which had indicated the number of patients with elevated levels of these biomarkers based on their laboratory cut-off values.

\section{Results}

We present our findings in two sections: "Meta-analyses" and "Systematic review" sections

\section{Meta-analyses}

Study selection

Figure 1 depicts the detailed process of data selection. Three-hundred and sixty-two (362) studies were retrieved in our initial search of PubMed and Embase, 315 of which remained after removing duplicates. In title/abstract screening, 257 papers did not meet our inclusion criteria and were excluded. Five of the studies entering full-text screening had either wrong study design or study population and were excluded. We also added one pre-print study regarding cardiac pathological findings from MedRvix [7]. We included a total of 54 studies in our qualitative synthesis, 35 of which were contained in our meta-analysis [3, 15-47].

\section{Features of the included studies}

Of the 54 selected studies for the review, 19 records were case reports, case series, or pathological reports. Among studies included in our meta-analysis, nine did not categorize their samples into subgroups, and the rest had a subgroup classification (Tables 1 and 2 in the Supplementary Materials 2 and 3 (S2 and S3). Five studies grouped their patients based on whether they survived or not, three depending on whether they had myocardial injury or high levels of cardiac biomarkers (troponin $\mathrm{T}$ or NT-pro BNP), four according to whether patients needed ICU admission or not, and eight had divided their patients based on the severity of manifestations. Three studies used a combination of these classifications and divided their patients into four or more subgroups. Moreover, in three remaining studies, age, the time elapsed from the onset of symptom, or requirement of supplemental oxygen were used to stratify patients.

\section{Risk of bias assessment}

Of the 35 studies we evaluated in the risk of bias assessment, 30 studies had a low risk of bias, while five records had a moderate risk of bias. None of the included studies were assessed as a study with a high risk of bias. The table of risk of bias assessment is available in Supplementary Material 4 (S4).

\section{Results of the meta-analyses}

Table 1 illustrates the summary of the results of the pooled analysis of the frequency of chest pain/chest tightness and palpitation as one of the initial manifestations, newly developed and pre-existing cardiovascular disease, and elevation of cardiac and inflammatory biomarkers. The forest plots are available in Supplementary Material 5 (S5).

Newly developed cardiovascular diseases or related symptoms Acute cardiac injury, with an estimated pooled frequency of $25.3 \%$ (95\% CI $19.5-31.1 \%$ ), was 


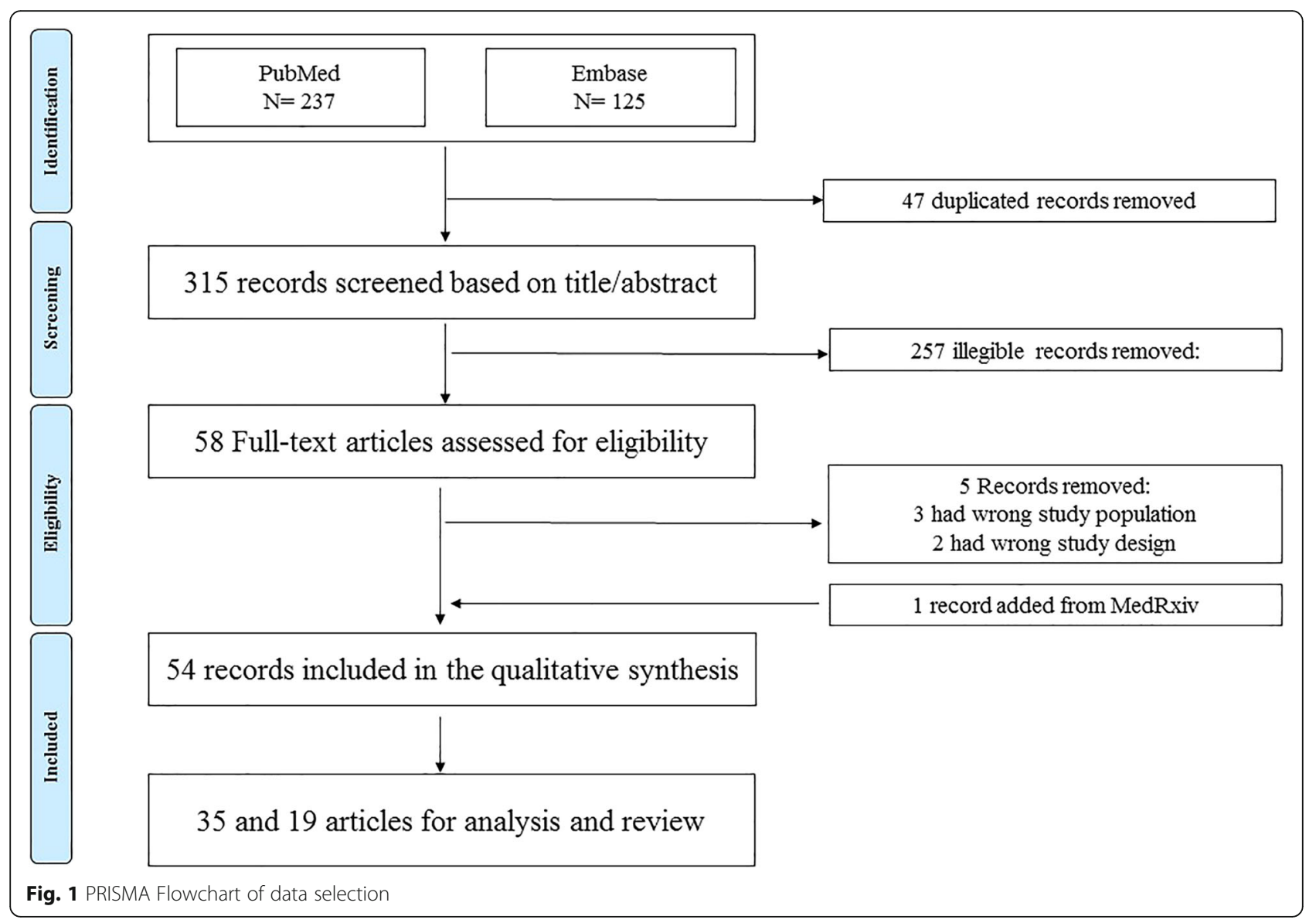

the most commonly reported cardiac complication of COVID-19. Although the pooled estimated frequency of arrhythmia was slightly higher than acute cardiac injury (26.1\%), it was only reported in four studies, and the 95\% confidence interval (CI) was equal to $2.5-51.5 \%$. Notably, there was significant heterogeneity in the estimates of newly developed acute cardiac injury and arrhythmia $\left(I^{2}=93 \%\right)$. Moreover, two studies with a total number of 367 patients had assessed newly developed heart failure due to COVID-19 infection, and the pooled frequency was calculated at 23.7\% (CI 19.3-28.0\%).

Among the cardiac manifestations as the initial presentation of COVID-19, frequency of chest pain or chest tightness and palpitation were investigated. A total of six studies had reported chest pain or chest tightness in COVID-19 patients. Our pooled frequency analysis showed that this presentation was observed as an initial manifestation in approximately one-fifth $(21.8 \%$, 95\% CI 19.3-28\%) of patients. Additionally, two other studies had reported palpitation as the initial presentation, the estimated pooled frequency of which equaled to $9.1 \%$ (95\% CI 6.2-12.1\%).
Pre-existing cardiovascular diseases, diabetes, and hypertension Hypertension was the most common preexisting comorbidity among COVID-19 patients with a pooled frequency of $29.2 \%$ (95\% CI $24.7-33.6 \%$ ), followed by diabetes with a pooled frequency of $13.5 \%(95 \%$ CI 11.5-15.4\%). Overall, fewer than one-fifth of patients had pre-existing cardiovascular diseases. The pooled frequency of cardiovascular diseases was estimated at $12.6 \%$ (95\% CI 10.0-15.2\%). Additionally, our analysis on the pooled frequency of heart failure using data of five studies, which had reported pre-existing heart failure, showed a pooled frequency of $6.3 \%$ (95\% CI 2.9-9.8\%). There was significant heterogeneity in the estimates of pre-existing cardiovascular diseases and hypertension $\left(I^{2} \geq 95 \%\right)$.

Elevated levels of cardiac and inflammatory biomarkers Figure 2 illustrates the pooled frequency of elevation of cardiac and inflammatory biomarkers. Among the biomarkers we investigated, ESR and CRP were the most commonly elevated biomarkers. The estimated pooled frequencies of patients with elevated ESR and CRP were $71.8 \%$ (95\% CI $59.0-84.6 \%$ ) and $75.4 \%$ (95\% CI $66-84 \%)$. Similarly, higher levels of serum 
Table 1 The summary of the pooled analysis of frequency of chest pain/chest tightness and palpitation as one of the initial manifestations, newly developed and pre-existing cardiovascular disease, and elevation of cardiac and inflammatory biomarkers in patients with COVID-19

\begin{tabular}{|c|c|c|c|c|c|}
\hline \multirow[t]{2}{*}{ Condition } & \multirow{2}{*}{$\begin{array}{l}\text { Number } \\
\text { of } \\
\text { included } \\
\text { studies }\end{array}$} & \multirow{2}{*}{$\begin{array}{l}\text { Total study } \\
\text { population } \\
\text { (event) } \\
\text { number }\end{array}$} & \multirow{2}{*}{$\begin{array}{l}\text { Pooled estimated } \\
\text { prevalence }(95 \% \mathrm{Cl})\end{array}$} & \multicolumn{2}{|c|}{ Test of heterogeneity } \\
\hline & & & & $\overline{l^{2}}$ & $p$ \\
\hline \multicolumn{6}{|c|}{ Chest pain/chest tightness and palpitation as one of the initial manifestations } \\
\hline Chest pain/chest tightness & 6 & $1599(387)$ & $21.8 \%(8.5 \%, 35.0 \%)$ & $99 \%$ & $<0.001$ \\
\hline Palpitation & 2 & $362(34)$ & $9.1 \%(6.2 \%, 12.1 \%)$ & $19 \%$ & $<0.001$ \\
\hline \multicolumn{6}{|l|}{ Newly developed } \\
\hline Arrhythmia & 4 & $444(93)$ & $26.1 \%(5.9 \%, 46.4 \%)$ & $97 \%$ & $<0.001$ \\
\hline Acute cardiac injury & 16 & $2647(671)$ & $25.3 \%(19.5 \%, 31.1 \%)$ & $93 \%$ & $<0.001$ \\
\hline Heart failure & 2 & $367(87)$ & $23.7 \%(19.3 \%, 28.0 \%)$ & $0 \%$ & $<0.001$ \\
\hline \multicolumn{6}{|l|}{ Pre-existing conditions } \\
\hline Hypertension & 30 & $10898(3165)$ & $29.2 \%(24.7 \%, 33.6 \%)$ & $96 \%$ & $<0.001$ \\
\hline Cardiovascular diseases & 27 & 7108 (699) & $12.6 \%(10.0 \%, 15.2 \%)$ & $95 \%$ & $<0.001$ \\
\hline Diabetes & 30 & $10806(1158)$ & $13.5 \%(11.5 \%, 15.4 \%)$ & $89 \%$ & $<0.001$ \\
\hline Heat failure & 6 & $1774(89)$ & $6.5 \%(3.3 \%, 9.7)$ & $95 \%$ & $<0.001$ \\
\hline \multicolumn{6}{|c|}{ Elevation of cardiac and inflammatory biomarkers } \\
\hline Interleukin- 6 & 3 & $574(391)$ & $65.9 \%(55.2 \%, 76.5 \%)$ & $86 \%$ & $<0.001$ \\
\hline CRP & 12 & $3227(2008)$ & $75.4 \%(66 \%, 84 \%)$ & $99 \%$ & $<0.001$ \\
\hline ESR & 3 & $767(547)$ & $71.8 \%(59.0 \%, 84.6 \%)$ & $92 \%$ & $<0.001$ \\
\hline serum ferritin & 3 & $538(375)$ & $70.3 \%(61.1 \%, 79.6 \%)$ & $81 \%$ & 0.006 \\
\hline NT-pro BNP & 7 & $1047(311)$ & $46.5 \%(28.9 \%, 64.2 \%)$ & $98 \%$ & $<0.001$ \\
\hline D-Dimer & 8 & $4789(2050)$ & $41.5 \%(31.0 \%, 52.1 \%)$ & $97 \%$ & $<0.001$ \\
\hline Lactate dehydrogenase & 9 & $2026(774)$ & $41.0 \%(28.8 \%, 53.2 \%)$ & $97 \%$ & $<0.001$ \\
\hline Cardiac Tn (I or T) & 10 & $1718(366)$ & $25.3 \%(17.6 \%, 33.1 \%)$ & $94 \%$ & $<0.001$ \\
\hline myoglobin & 5 & $1076(176)$ & $19.1 \%(11.6 \%, 26.6 \%)$ & $91 \%$ & $<0.001$ \\
\hline Creatine kinase & 10 & $1617(230)$ & $15.9 \%(10.5 \%, 21.3 \%)$ & $90 \%$ & $<0.001$ \\
\hline Creatine kinase-MB & 2 & $382(302)$ & $66.2 \%\left(6.9 \%-100.0 \%{ }^{a}\right)$ & $99 \%$ & $<0.001$ \\
\hline TNF-a & 2 & $275(472)$ & $58.3 \%$ (53.8\%-62.7\%) & $0 \%$ & 0.7 \\
\hline
\end{tabular}

Abbreviations: NT-pro BNP N-terminal pro B-type natriuretic peptide, CRP C-Reactive Protein, Tn troponin, TNF- $a$ Tumor Necrosis Factor-a

${ }^{\mathrm{a}}$ Due to the high heterogeneity the upper limit of $95 \% \mathrm{Cl}$ was higher than $100 \%$

ferritin was observed in approximately $70.3 \%(95 \%$ CI $61.1-64.2 \%)$ of the patients. Elevation of IL-6 was present in about two-thirds of patients $(65.9 \%, 95 \%$ CI $55.2 \%, 76.5 \%)$.

Moreover, among cardiac biomarkers, increased levels of NT-pro BNP, D-dimer, and LDH were found in approximately $40 \%$ of patients. The estimated pooled frequencies of elevation of NT-pro BNP, D-dimer, and LDH were equal to $46.5 \%$ (95\% CI $28.9-64.2 \%$ ), $41.5 \%$ (95\% CI $31.0-52.1 \%$ ), and $41.0 \%$ (95\% CI $28.8-53.2 \%$ ), respectively. Elevation of cardiac troponins was observed in approximately onequarter of patients $(25.3 \%$, 95\% CI 17.6-33.1\%). Additionally, we identified and analyzed the findings of five studies that had investigated the number of patients with increased myoglobin levels. The estimated pooled frequency of elevated myoglobin was at near $19.1 \%$ (95\% CI $11.6-$ 26.6\%). Lastly, we found ten studies reporting the number of patients with elevated CK levels and two studies reporting the number of patients with elevated CK-MB levels. The estimated pooled frequency of elevation of CK and CK-MB were equaled to $15.9 \%$ (95\% CI $10.5-$ $21.3 \%$ ) and $66.2 \%$ (95\% CI 6.9-125.6\%), respectively. Of note, Chen et al. reported reduction of CK levels in $23 \%$ of their patients [18]. As the wide CI range and high heterogeneity score $\left(I^{2}=99 \%\right)$ show, the results of this analysis cannot be very reliable and additional original investigations are required in this regard. Notably, there was significant heterogeneity in the estimates of the frequency of increased cardiac and inflammatory biomarkers ( $\left.86 \% \leq I^{2} \leq 99 \%\right)$. 


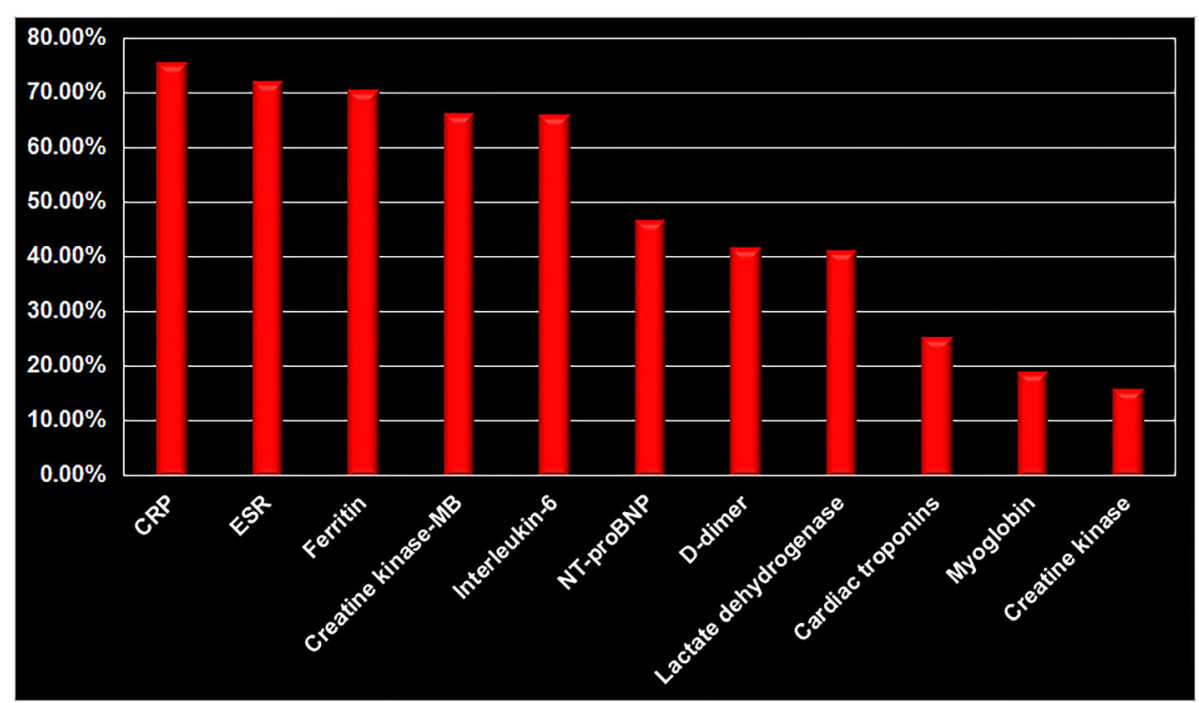

Fig. 2 Pooled frequency of elevated cardiac and inflammatory biomarkers

Only two studies had measured the levels of TNF- $\alpha$. Pooled frequency of elevated levels of TNF- $\alpha$ was $58.3 \%$ (95\% CI 53.8-62.7\%) [19, 33].

Association of newly developed acute cardiac injury, pre-existing cardiovascular diseases, hypertension, and diabetes with disease severity and survival Figure 3 depicts the odds ratio for death and developing severe forms of COVID-19 infection according to the presence of newly developed acute cardiac injury, hypertension, diabetes mellitus, and pre-existing cardiovascular diseases. The forest plots showing the odds ratio for death according to newly developed acute cardiac injury, pre-existing cardiovascular disease, hypertension, and diabetes mellitus are available in Supplementary Material 6 (S6).

Newly developed acute cardiac injury: association with survival and severity The development of acute cardiac injury increased the risk of mortality by near 20 times (OR 19.64, 95\% CI 10.28-37.53, $P<0.001$ ). Patients developing acute cardiac injury had a much higher risk of being admitted to ICU (OR 13.5, 95\% CI 3.6150.52, $P<0.001)$. Studies included in the analysis of

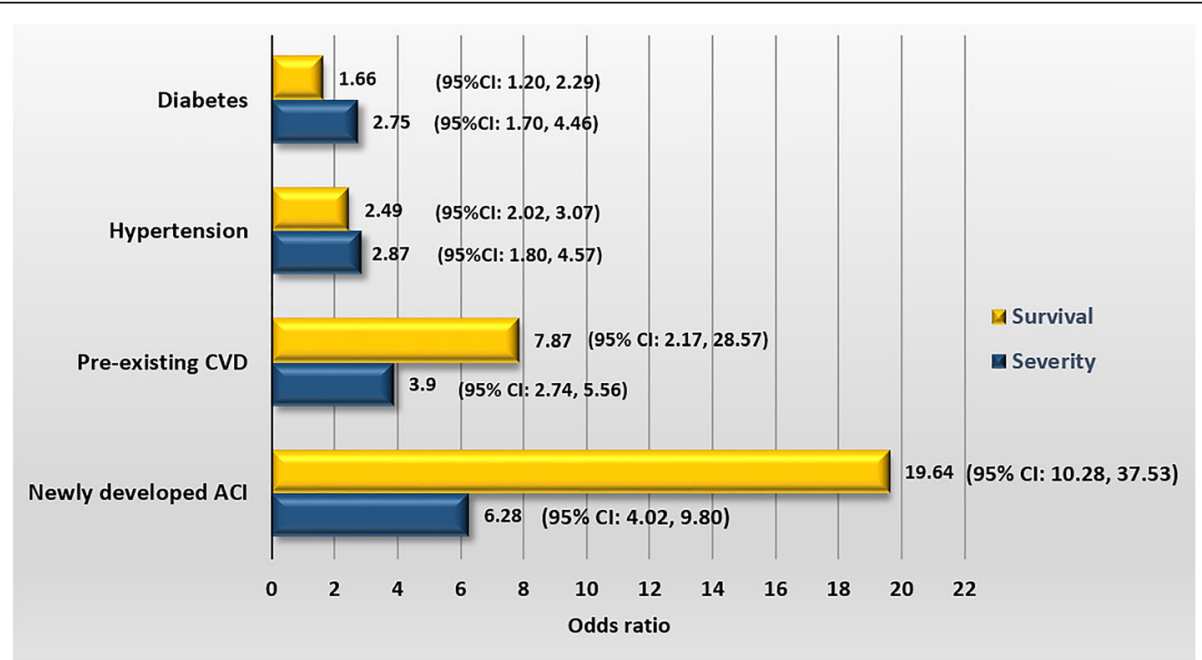

Fig. 3 The odds ratio for death and developing severe forms of COVID-19 infection according to the newly developed acute cardiac injury, hypertension, diabetes mellitus, and pre-existing cardiovascular diseases (ACl acute cardiac injury, CVD cardiovascular disease, Cl confidence interval) 
assessing the effect of acute cardiac injury on the risk of being admitted to ICU were homogenous $\left(I^{2}=0 \%\right)$. When we added one study comparing the incidence of acute cardiac injury between severe and non-severe patients, we found that development of acute cardiac injury increased the occurrence of more severe presentation of the disease more than six times (OR 6.28, 95\% CI 4.229.8, $P<0.001$ ) (Fig. 4).

Pre-existing cardiovascular diseases: association with survival and severity Pre-existing cardiovascular diseases pose a significant risk of mortality. Patients with these conditions were near eight times more likely to have a fatal outcome (OR 7.87, 95\% CI 2.17-28.57, $P=$ 0.002). Studies comparing pre-existing cardiovascular diseases between deceased and survived patients were moderately heterogeneous $\left(I^{2}=54 \%, P=0.07\right)$. Similarly, patients with pre-existing cardiovascular diseases were about four times more likely to be categorized in the ICU or severe groups (OR 3.9, 95\% CI 2.74-5.56, $P$ $<0.001)$. Patients with pre-existing cardiovascular diseases were approximately three times more likely to be admitted to the ICU (OR 3.33, 95\% CI 1.81-6.11, $P<$ 0.001 ) and four times more likely to develop severe forms of the disease (OR 4.18, 95\% CI 2.7-6.48, $P<$ 0.001) (Fig. 4).

Hypertension: association with survival and severity We included eight studies with low heterogeneity $\left(I^{2}=\right.$ $25 \%)$ to assess the role of hypertension in increasing the mortality rate and found that patients with hypertension were more than twice more likely to die from COVID19 compared to other patients (OR 2.49, 95\% CI $2.02-$ 3.07, $P<0.001)$.

Likewise, patients with hypertension were about three times more likely to be categorized in the ICU or severe groups (OR 2.87, 95\% CI 1.80-4.57, $P<0.001)$. Patients with hypertension were approximately 3.8 times more likely to be admitted to the ICU (OR 3.79, 95\% CI 2.50$5.74, P<0.001)$ and 2.5 times more likely to develop severe forms of COVID-19 infection (OR 2.54, 95\% CI 1.35, 4.80, $P<0.001$ ) (Fig. 4).

Diabetes: association with survival and severity Six studies with low heterogeneity $\left(I^{2}=0 \%\right)$ had reported number of patients with diabetes in deceased and survived groups. We found that patients with diabetes were

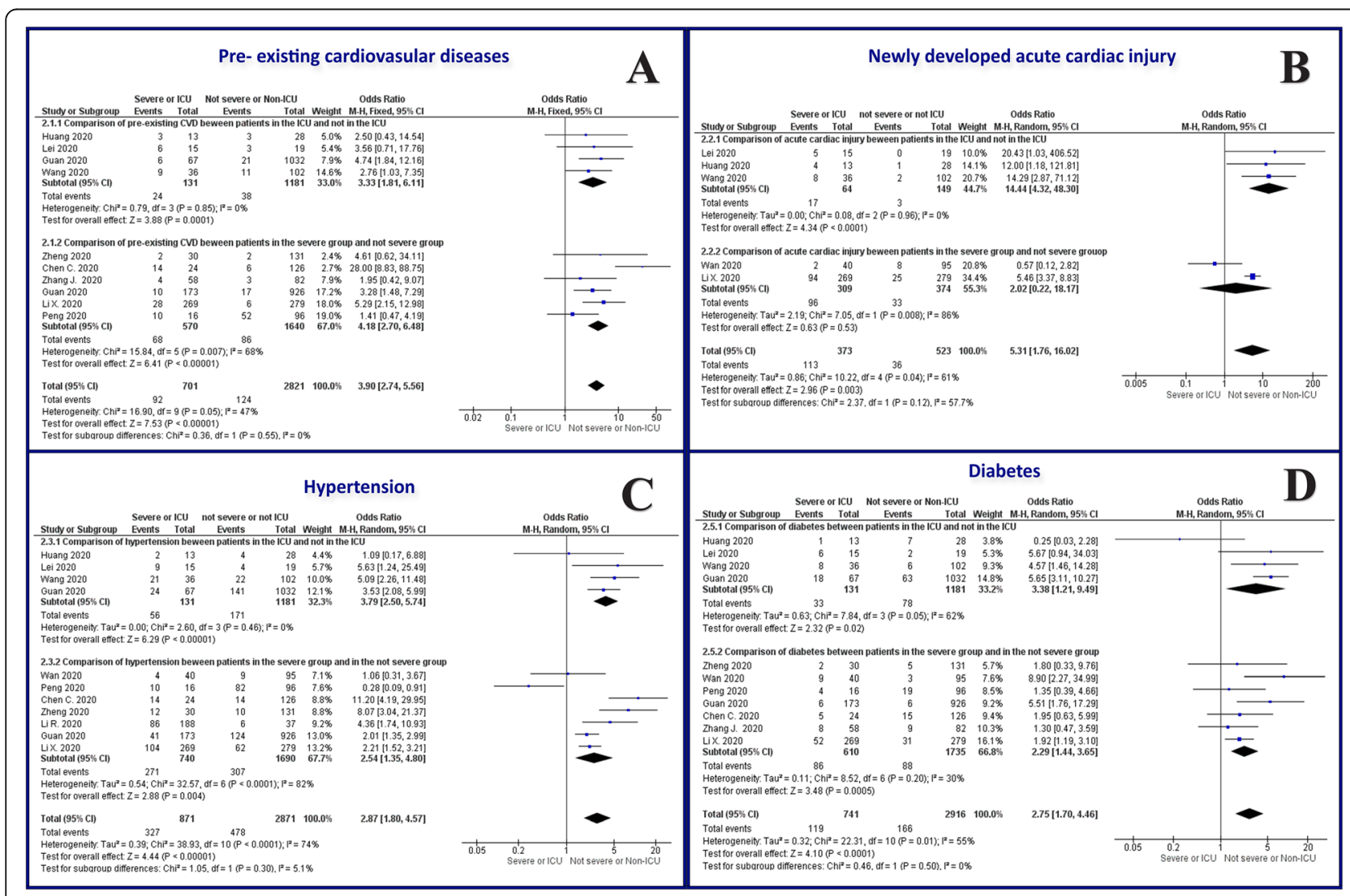

Fig. 4 Forest plots showing the odds ratio for severity according to the newly developed acute cardiac injury, pre-existing cardiovascular disease, hypertension and diabetes mellitus 
slightly more likely to die from COVID-19 compared to other patients (OR 1.66, 95\% CI 1.20-2.29, $P<0.001$ ).

Similarly, patients with diabetes were near three times more likely to be categorized in the ICU or severe groups (OR 2.75, 95\% CI 1.70-4.46, $P<0.001$ ). They were approximately 3.38 times more likely to be admitted to the ICU (95\% CI 1.21-9.49, $P=0.02)$ and 2.29 times more likely to develop severe forms of COVID-19 infection (95\% CI 1.44, 3.65, $P<0.001$ ) (Fig. 4).

Elevated levels of cardiac and inflammatory biomarkers level: association with survival The levels of cardiac biomarkers, including cardiac troponin $(\mathrm{SMD}=2.96,95 \%$
CI $0.47-5.45, P=0.02)$, myoglobin $(\mathrm{SMD}=1.64,95 \% \mathrm{CI}$ $1.34-1.93, P<0.001)$, LDH (SMD $=1.54,95 \%$ CI $0.76-$ 2.32, $P<0.001)$, NT-pro BNP (SMD $=1.13,95 \% \mathrm{CI}$ $0.64-1.61, P<0.001)$, and CK (SMD $=1.13,95 \% \mathrm{CI}$ $0.64-1.61, P<0.001)$ were significantly higher in the deceased group (Fig. 5).

We included elevated levels of troponin I, T, and highsensitivity troponin (either I or T) as cardiac troponins.

Similarly, the levels of inflammatory markers, including IL-6 (SMD = 1.37, 95\% CI 1.05-1.69, $P<0.001)$, ferritin $(\mathrm{SMD}=1.13,95 \% \mathrm{CI} 0.78-1.49, P<0.001)$, CRP $(\mathrm{SMD}=1.04,95 \%$ CI $0.64-1.44, P<0.001)$, and ESR $(\mathrm{SMD}=0.38,95 \% \mathrm{CI} 0.15-0.60, P<0.001)$, were significantly higher in the deceased group (Fig. 6).

\section{Cardiac troponin}



\section{Myoglobin}

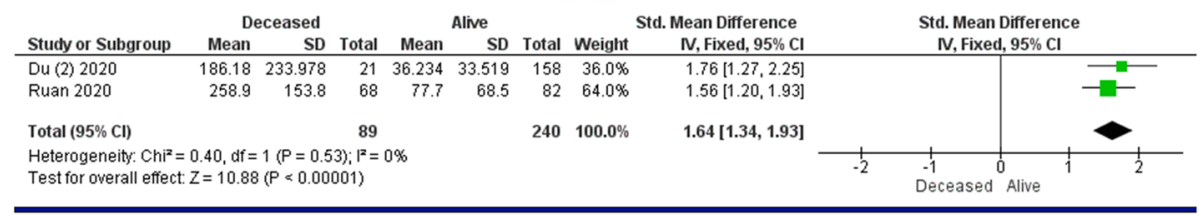

Lactate dehydrogenase

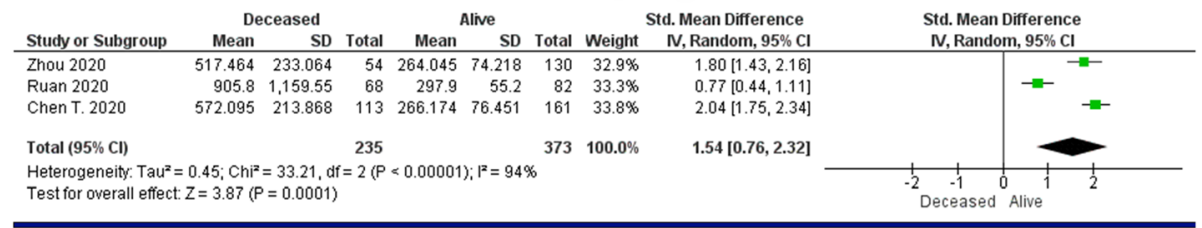

\section{NT-proBNP}

\begin{tabular}{|c|c|c|c|c|c|c|c|c|c|c|c|c|}
\hline \multirow[b]{2}{*}{ Study or Subgroup } & \multicolumn{3}{|c|}{ Deceased } & \multicolumn{3}{|c|}{ Alive } & \multicolumn{2}{|r|}{ Std. Mean Difference } & \multirow{2}{*}{\multicolumn{4}{|c|}{ Std. Mean Difference }} \\
\hline & Mean & SD & Total & Mean & SD & Total & Weight & IV, Random, $95 \% \mathrm{CI}$ & & & & \\
\hline He 2020 & $1,213.54$ & $1,502.233$ & 26 & 322.759 & 402.844 & 28 & $38.0 \%$ & $0.81[0.25,1.37]$ & & &  & \\
\hline Chen T. 2020 & $1,013.6$ & $1,072.11$ & 113 & 93.42 & 123.42 & 161 & $62.0 \%$ & $1.32[1.06,1.59]$ & & & & \\
\hline Total $(95 \% \mathrm{Cl})$ & & & 139 & & & 189 & $100.0 \%$ & $1.13[0.64,1.61]$ & & & & \\
\hline $\begin{array}{l}\text { Heterogeneity. Tau } \\
\text { Test for overall effect }\end{array}$ & $\begin{array}{l}0.08 ; \text { Chi }^{2} \\
z=4.56(P\end{array}$ & $\begin{array}{l}=2.62, \mathrm{df}=1 \\
0<0.00001)\end{array}$ & & & & & & & $\begin{array}{c}1 \\
-2\end{array}$ & $\begin{array}{l}1 \\
-1 \\
\text { Deceased }\end{array}$ & Alive & $\frac{1}{2}$ \\
\hline
\end{tabular}

\section{Creatine kinase}

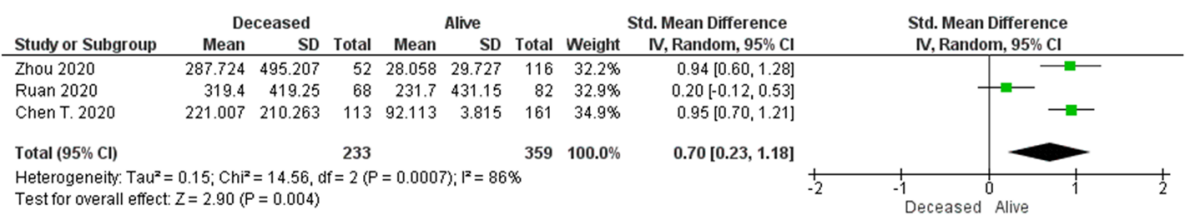

Fig. 5 Forest plots showing the standardized mean difference of cardiac biomarkers (troponin, myoglobin, LDH, NT-proBNP and CK) in the severe or ICU group compared with patients in the non-severe or non-ICU group 


\section{Interleukin-6}

\begin{tabular}{|c|c|c|c|c|c|c|c|c|c|c|c|}
\hline \multirow[b]{2}{*}{ Study or Subgroup } & \multicolumn{3}{|c|}{ Deceased } & \multicolumn{3}{|c|}{ Alive } & \multicolumn{2}{|r|}{ Std. Mean Difference } & \multirow{2}{*}{\multicolumn{3}{|c|}{$\begin{array}{l}\text { Std. Mean Difference } \\
\text { N, Random, } 95 \% \mathrm{Cl}\end{array}$}} \\
\hline & Mean & SD & Total & Mean & SD & Total & Weight & $\mathrm{N}$, Random, $95 \% \mathrm{Cl}$ & & & \\
\hline Zhou 2020 & 10.9646 & 5.2554 & 54 & 6.4054 & 2.1728 & 137 & $31.9 \%$ & $1.36[1.02,1.70]$ & & & -- \\
\hline Ruan 2020 & 11.4 & 4.25 & 68 & 6.8 & 1.805 & 161 & $33.4 \%$ & $1.66[1.34,1.98]$ & & & $\rightarrow-$ \\
\hline Chen T. 2020 & 85.7173 & 82.6035 & 113 & 14.4751 & 16.6067 & 82 & $34.6 \%$ & $1.11[0.81,1.42]$ & & & $\rightarrow-$ \\
\hline Total $(95 \% \mathrm{Cl})$ & & & 235 & & & 380 & $100.0 \%$ & $1.37[1.05,1.69]$ & & & \\
\hline $\begin{array}{l}\text { Heterogeneity. } \mathrm{Tau}^{2}= \\
\text { Test for overall effect: }\end{array}$ & $\begin{array}{l}0.05 ; \mathrm{Chi}^{2} \\
\mathrm{Z}=8.42(\mathrm{P}\end{array}$ & $\begin{array}{l}=5.86, d f= \\
P<0.00001\end{array}$ & $\begin{array}{l}=2(P= \\
1)\end{array}$ & $=0.05) ; 1^{2}=$ & & & & & $\begin{array}{c}1 \\
-2\end{array}$ & $\begin{array}{l}-1 \\
\text { Deceased Alive }\end{array}$ & 1 \\
\hline
\end{tabular}

\section{Ferritin}

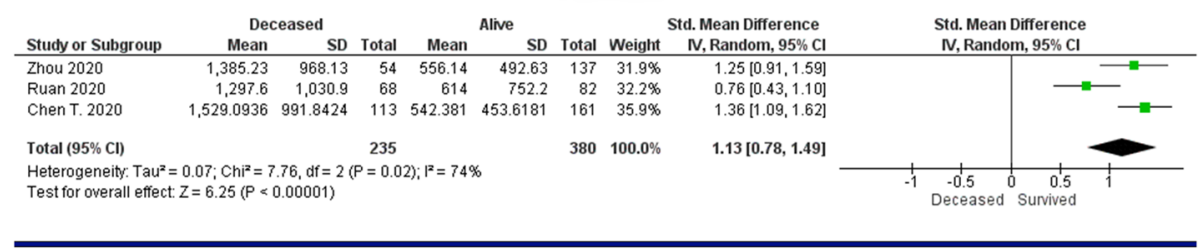

\section{C-reactive protein (CRP)}

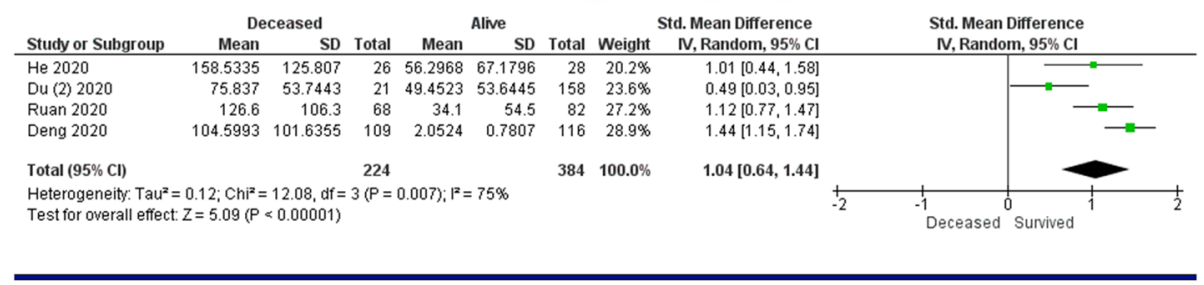

Erythrocyte sedimentation rate (ESR)

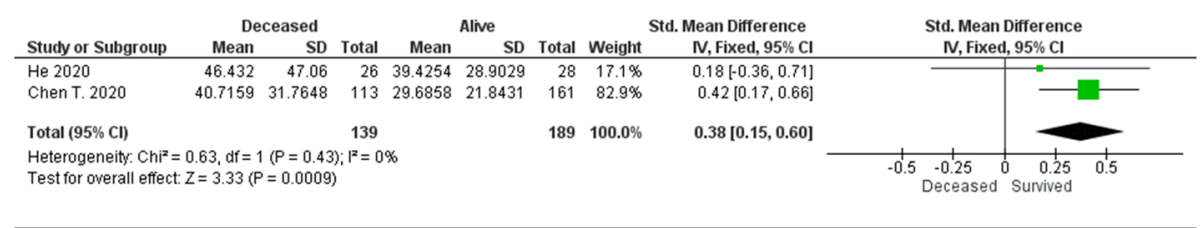

Fig. 6 Forest plots showing the standardized mean difference of interleukin-6, ferritin, CRP and ESR between the deceased and survived patients

Cardiac biomarkers levels: association with severity Overall, LDH levels were higher in patients classified as the ICU or severe groups (SMD $=0.75,95 \%$ CI 0.34-1.16, $P<0.001)$. Notably, the SMD in the severe or non-severe subgroup (SMD $=0.96,95 \%$ CI $0.4-1.52, P<0.001$ ) was larger than the SMD in the ICU or not ICU subgroup $(\mathrm{SMD}=0.5,95 \%$ CI 0.05-0.96, $P=0.03)$.

Overall, CK levels were higher in patients classified as the ICU or severe groups (SMD $=0.55$, 95\% CI $0.27-$ $0.82, P<0.001)$. Additionally, the SMD in ICU or not ICU subgroup (SMD $=0.58,95 \%$ CI 0.28-0.88, $P<$ 0.001 ) was quite similar to the severe or non-severe subgroup (SMD $=0.54,95 \%$ CI 0.09-0.99, $P=0.02$ ).

Two studies had assessed the difference between CK$\mathrm{MB}$ levels between the severe and non-severe group of the patients. CK-MB levels were higher in the patients with severe forms of COVID-19 (SMD $=0.36,95 \% \mathrm{CI}$ $0.12-0.6, P<0.001)$. When we added the only study which had compared the levels of CK-MB between ICU and non-ICU patients, the total SMD was 0.55 (95\% CI 0.09-1.01, $P=0.02$ ) (Fig. 7).

Pooled frequencies of acute cardiac injury, acute hepatic injury, and acute kidney injury Given the cardio-hepatic and cardio-renal interactions, we also analyzed the pooled frequency of acute liver injury and acute kidney injury in our selected studies [48-52].

While acute cardiac injury was reported in $25.3 \%$ (95\% CI $19.5-31.1 \%$ ) of patients, acute liver injury was reported in $22.2 \%$ (95\% CI 13.5-31.0\%) and acute kidney injury was stated in $8.8 \%$ of studies (95\% CI $5.4-12.2 \%$ ).

Funnel plots showing publication bias of studies are shown in Supplementary Material 7 (S7). 


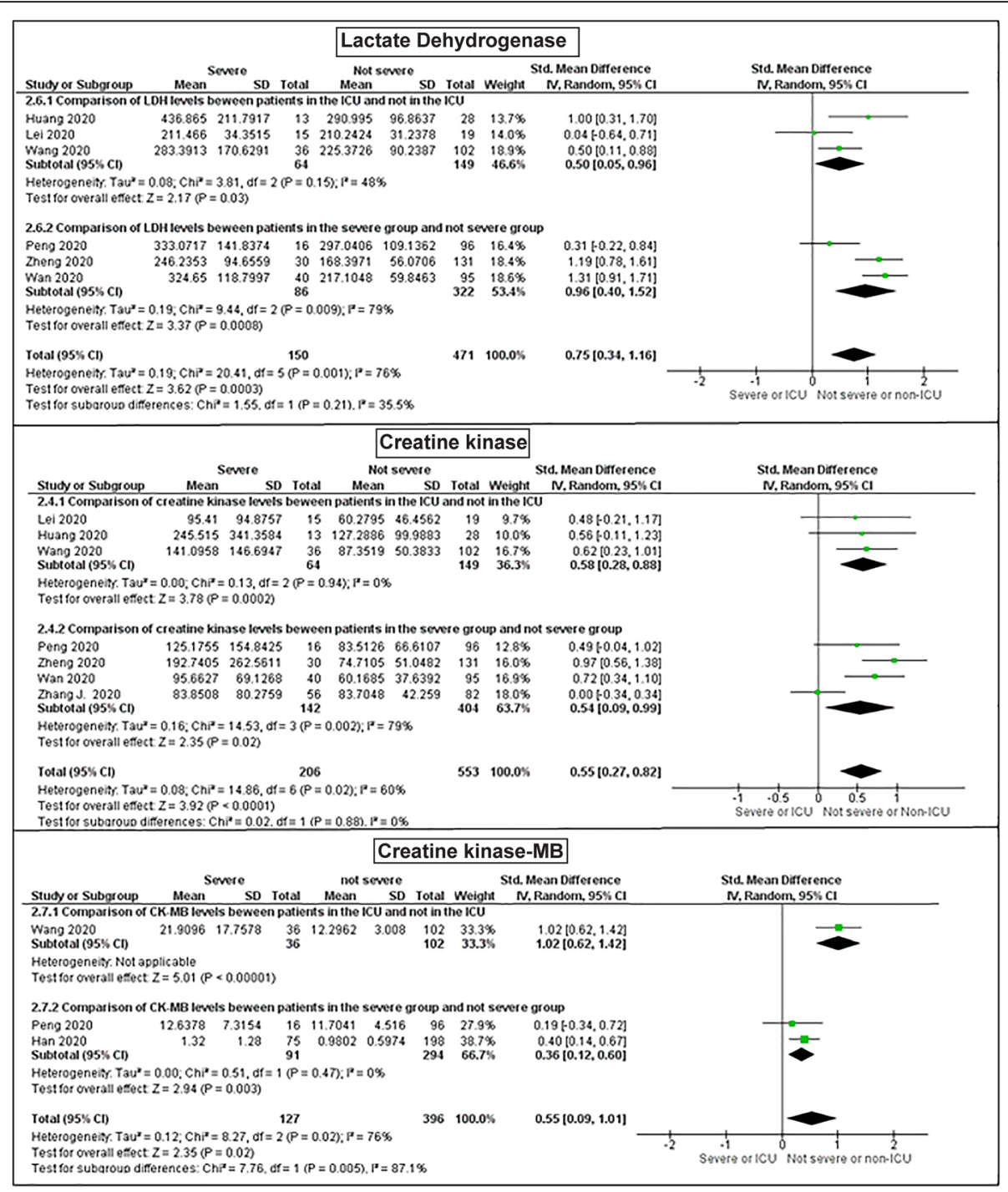

Fig. 7 Standard mean difference of LDH, CK and CK-MB between COVID-19 patients with severe disease in comparison with non-severe disease

\section{Systematic review}

Spectrum of newly developed cardiovascular diseases and the mechanisms of acute cardiac injury (adult versus pediatric population)

A diverse range of cardiovascular disease has been reported in patients with COVID-19 which encompasses acute myocarditis (including acute lymphocytic myocarditis) [53], fulminant myocarditis [15, 24, 37, 54-56], acute myocardial infarction type 2 [7], acute myopericarditis [46], acute pulmonary embolism [57-60], cardiac tamponade [46], cardiogenic shock [61, 62], cardiomyopathy [63], heart failure, pericardial effusion, pulmonary hypertension, reverse Takotsubo cardiomyopathy [64], and right ventricular dysfunction $[62,65]$.

Left ventricular failure was more commonly reported in COVID-19 patients than right ventricular dysfunction. However, to date, the majority of cases with right ventricular failure were secondary to acute pulmonary embolism [65, 66]. Nevertheless, Fried and his colleagues reported myopericarditis in a 64-yearold patient who developed biventricular failure and was successfully managed using an intra-aortic balloon pump (IABP) [62].

In the pediatric population, there was a case of mild elevation of troponin I in a 55-day-infant with excellent outcome and discharge from the hospital [67]. However, both Kawasaki-like disease and Kawasaki shock-like syndrome have been reported with COVID-19. Jones et al. reported a 6-month-old female infant with the typical symptoms of Kawasaki disease that was tested positive for COVID-19. Her echocardiogram was normal [68]. Riphagen and her colleagues reported 8 patients with shock, aged 4 to 14 years, who had initially presented with persistent fever, rash, inflammation of the conjunctiva, peripheral edema, 
and pain in the extremities. All except one had prominent gastrointestinal symptoms, and all except one weighed above 75th percentile. All had elevated levels of cardiac troponins and developed warm shock. None of them tested positive for COVID-19. However, a 14-year-old boy with $95 \mathrm{~kg}$ weight and a BMI of $33 \mathrm{~kg} / \mathrm{m}^{2}$, who underwent ECMO and died of cerebral infarction was tested positive postmortem, and another case was positive for COVID-19 after discharge. Antibody test was positive for COVID-19 in all the eight patients. Their echocardiographic findings included left ventricular and/or right ventricular dysfunction and increased brightness of walls of the coronary arteries. The authors suggested that COVID-19 can produce a "hyper-inflammation syndrome" that involves multiple organs, mimicking Kawasaki disease shock syndrome [69].

The exact mechanisms of cardiac injury in patients with COVID-19 are not confirmed. However, it is speculated that cardiac injury can occur through one or more of the putative mechanisms [28, 70, 71]: direct invasion by the virus, indirect damage due to the systemic inflammatory syndrome and cytokine storm, dysregulation of renin-angiotensin-aldosterone system, hypoxia-induced cardiac injury, microvasculature damage of the heart, stress-induced cardiomyopathy, and cardiac damage secondary to multi-organ failure.

Timing of the appearance of the cardiac complications, early versus late stage, may serve as a hint to the diagnosis of the putative mechanism/s $[72,73]$.

\section{Spectrum of newly developed arrhythmias and electrocardiographic changes}

Dynamic changes in ECG are of paramount importance during COVID-19 and imply acute cardiac derangement. Patients with COVID-19 are at risk of arrhythmias and ECG changes due to the disease itself or because of the medications used for its prevention or treatment, such as chloroquine, hydroxychloroquine, and azithromycin. These three medications can prolong QT interval and predispose the patient to torsades de pointes [74]. Nevertheless, to date, no case of torsades de pointes due to QTc prolongation secondary to consumption of these drugs has been reported in these patients.

Sinus tachycardia is the most common rhythm disturbance reported in patients with COVID-19. Moreover, a variety of other rhythm disorders and electrocardiographic alterations have been reported in patients with COVID-19 such as supraventricular tachycardia [62, 63], ventricular tachycardia, first-degree atrioventricular block (AVB), temporary second-degree AVB, reversible complete heart block, generalized STelevation masquerading ST-elevation myocardial infarction (STEMI), triangular-type ST-elevation myocardial infarction type 2, S1Q3T3 pattern mimicking acute pulmonary embolism, non-specific ST and T wave changes, diffuse $U$ waves in the presence of a QTc of $0.45 \mathrm{~ms}$, and pulseless electrical activity $[63,75]$.

\section{Spectrum of pathologic findings on cardiac biopsy or autopsy}

By 23rd of April 2020, there are seven studies reporting the cardiac pathological findings $[7,61,64,76-79]$. The summary of these studies is tabulated in supplementary Table 3 in Supplementary Material 8 (S8). Two of these have also performed electron microscopic examination $[61,79]$. Only in one case with fulminant myocarditis and cardiogenic shock, virus was present in the pericytes [61]. No obstruction or thrombosis of epicardial coronary arteries were reported. Prominent infiltration of $\mathrm{T}$ lymphocytes was present in only one case which presented as reverse Takutsubo cardiomyopathy [53].

\section{Discussion}

This study showed that compared to the liver and kidney, the heart was the second most commonly involved organ affected by COVID-19 after the lungs. Slightly more than one-fourth of the hospitalized patients with COVID-19 develop CVD and arrhythmia, which increased the mortality by nearly 20 times and the need for ICU admission by 13.5 times. Hypertension was present in slightly less than one-third of admitted patients and led to increased mortality and the need for ICU admission by approximately 2.5- and 4-folds, respectively. However, this association may be partly due to the fact that the incidence of hypertension increases with aging [80]. It is already known that mortality is higher in older patients with COVID-19 [81]. The relationship among inflammation, oxidative stress, and vascular dysfunction, known as vascular health triad, is reported as a common mechanism between aging and hypertension [82].

Patients with pre-existing heart failure had 8-fold more death and nearly 3.5-fold more need for the ICU admission.

In a systematic review and meta-analysis, Santoso et al. studied 2389 patients, and by calculating the risk ratio showed that in patients with cardiac injury, mortality and need for ICU admission were 7.95 times and 7.94-fold more likely, respectively [83].

Not only do cardiovascular complications increase morbidity and mortality, but they also enhance the risk of sepsis and septic shock. This may be explained by the prolonged period of hospitalization and/or use of different invasive devices to support the circulatory failure [56, 61].

Even after discharge, patients with a history of myocarditis may develop myocardial scars, which predispose them to cardiac arrhythmia. Follow-up investigation by cardiac magnetic resonance imaging is recommended in 
order to determine the risk of cardiac arrhythmias [84]. Another reason for the necessity of follow-up is to ensure that acute myocarditis of COVID-19 does not evolve into dilated cardiomyopathy in later life [85]. Furthermore, cardiac magnetic resonance imaging can be of great help in the diagnosis of acute myocarditis in hospitalized patients; nevertheless, it was used scarcely [86].

Pulmonary embolism was frequently reported and should be considered in any patient with COVID-19 who experience sudden deterioration of clinical condition associated with an acute drop in oxygen saturation or those with significantly elevated levels of D-dimer.

COVID-19-associated coagulopathy (CAC), the etiology of which is multifactorial and not yet completely understood, has been reported with a spectrum of manifestations ranging from hypercoagulability (in the vast majority of the reported cases) to less common reports of bleeding, particularly in patients treated with ECMO or anticoagulants [87]. The triad of Virchow, including endothelial damage, alterations in blood flow and presence of prothrombotic components in the circulation, appears to have a substantial role in the development of CAC [87].

The spectrum of presentation of hypercoagulability states in COVID-19 encompasses a wide range that spans from localized microvascular thrombosis in the lungs or pulmonary intravascular coagulopathy (PIC) to systemic venous and arterial thrombosis, including aortic thrombosis [88-90]. Development of COVID19-associated coagulopathy is associated with a worse prognosis [91]. Hence, prophylactic treatment with low molecular weight heparin is recommended for all hospitalized COVID-19 patients, unless there is a contraindication [92, 93]. Anticoagulant therapy has been shown to be associated with improved survival [94].

Our meta-analyses demonstrated that IL-6, which has a critical role in cytokine release syndrome, was elevated in approximately two-thirds of the hospitalized patients. Coomes and his colleagues, in a recent systematic review and meta-analysis on the role of IL-6 in patients with COVID-19, showed that IL-6 was 2.9 times higher in patients with complicated COVID-19, compared with the non-complicated group. They also found that IL-6 levels were 3.24-fold higher in the 33 patients who required ICU admission in comparison with 507 patients who did not need to be admitted in the ICU [95]. Increased IL-6 can also explain the speculative cardiac microvascular abnormalities in patients with COVID-19 [27]. Zhang et al. highlighting the substantial role of IL-6, described the pathophysiology of cytokine release syndrome in patients with COVID-19 and severe clinical course. They proposed that tocilizumab, a recombinant humanized monoclonal antibody against the receptor of IL-6, can serve as a potentially effective treatment for cases presenting as severe COVID-19 [96]. Given the central role of IL-6 in cytokine release syndrome and the safety of tocilizumab in children and adult patients, Liu et al. also proposed tocilizumab as a treatment for patients with severe COVID-19 [97].

We observed higher levels of cardiac troponin, myoglobin, LDH, NT-proBNP, CK, and IL-6, in the deceased patients in comparison with the survived. Li and his colleagues showed that cardiac troponins and NT-proBNP were higher in the deceased patients with COVID-19. They also reported that the dynamic rise in the latter biomarkers was only observed in the deceased group [15]. Likewise, Guo et al. studied 187 patients with COVID-19 and observed that dynamic changes or rising levels of NT-proBNP and cardiac troponin T were significantly higher in the deceased patients [98].

We found a sharp contrast between frequency, severity, and outcome of cardiac involvement due to COVID19 in pediatric versus adult population [99].

In a systematic review of children with COVID-19, Ludvigsson et al. did not report even one case of COVID-19-induced cardiac injury in the pediatric age range. They cited the study of Dong et al. as the largest study on children, the study in which only 3 cases of the 724 confirmed cases had the critical disease, none of them had cardiac injury $[100,101]$. Shekerdemian et al. reported 48 children with COVID-19 who were admitted to ICU and $83 \%$ of whom had significant underlying comorbidities, including congenital heart disease and cardiomyopathy in three cases. Although they reported a fatality rate of $4 \%$, they have not delineated whether the deceased patients were those with prior cardiac disease. Furthermore, except the one patient with underlying cardiomyopathy who underwent veno-arterial ECMO for treatment of cardiogenic shock, no further information regarding acute cardiac injury is provided [102].

Given the fact that angiotensin-converting enzyme 2 (ACE2) functions as the receptor for the entry of SARS$\mathrm{CoV}-2$ into the cell, the answer may be partly hidden in the age-related differences in the renin-angiotensinaldosterone system (RAAS) [103]. This hypothesis is supported by the evidence that shows the elderly are predisposed to severe forms of the COVID-19 [104106]. Furthermore, Musso et al. reported that advancing age adversely affects the RAAS [107]. Similarly, senescence-related changes in the immune function may also be contributing [108].

Nevertheless, it seems that although mortality due to direct viral invasion to the heart is not reported in children, the catastrophic effects of hyper-inflammatory response with multi-organ involvement including the heart, the so-called COVID-19 pediatric hyperinflammatory shock syndrome, can be life-threatening. 
In fact, both Kawasaki-like disease and Kawasaki shocklike syndrome have been reported with COVID-19. These findings may also potentially shed light on the role of viruses in the pathogenesis of Kawasaki disease.

\section{Triage risk stratification tool for patients with COVID-19} and cardiovascular disease

Time of presentation of the cardiac disorders (early stage versus late stage) and levels of various cardiac and inflammatory biomarkers can serve as clues to the putative underlying mechanism/s. To detect patients at the highest risk at the earliest, i.e., at triage, a simple and practical plan is necessary to guide the clinician on the minimal essential initial laboratory work-up as a guide for pathophysiologically targeted treatment.
Figure 8 shows a proposed triage risk stratification tool for patients with COVID-19 and CVD.

Two considerations should be taken into account when using this tool. The first is that the laboratory investigations in this tool are in addition to the routine laboratory evaluations such as CBC, ESR, CRP, and blood glucose. Secondly, it should be borne in mind that for consideration of mechanical circulatory support, the conventional indications and contraindications in patients with COVID-19, in addition to the precautions for prevention and treatment of infections, should be strictly followed [109-111].

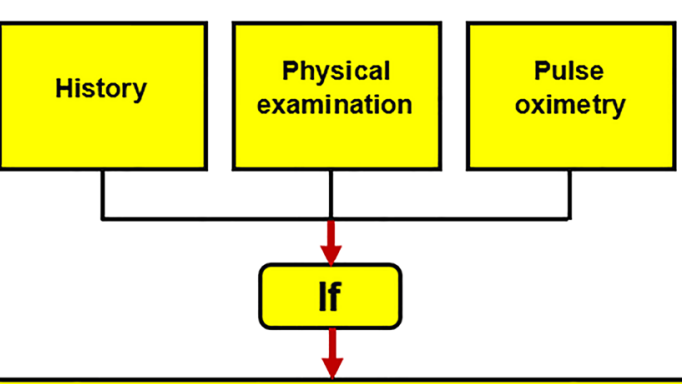

Severe or critical disease + pre-existing CVD and/or hypertension \pm other known risk factors, such as diabetes, obesity and older age)
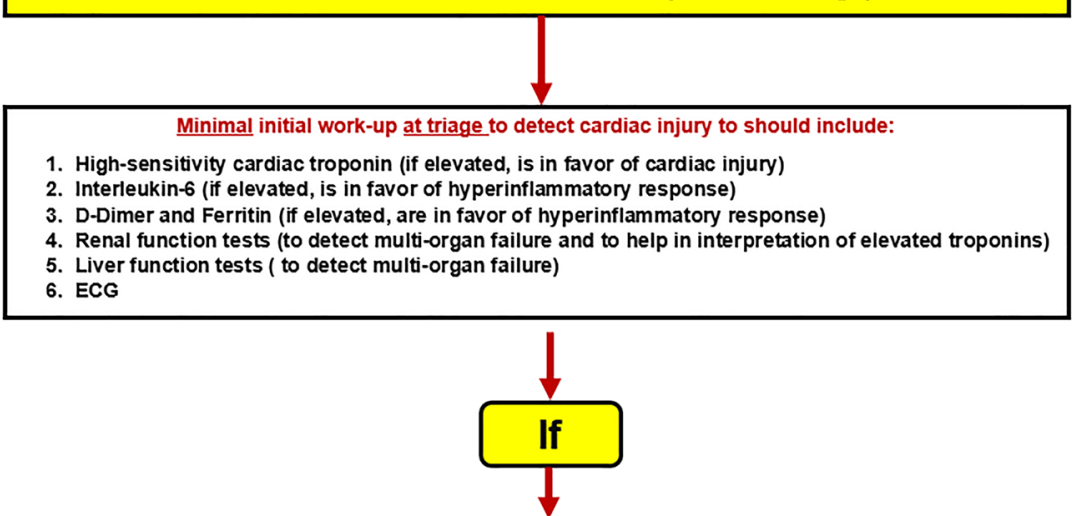

If marked elevation of hs-cTn, IL-6, D-dimer and Ferritin are present

1. Consider serial measurement of cardiac troponin (dynamic escalation shows worse outcome)

2. Perform echocardiography

3. In the presence of ECG findings of myocardial infarction, perform coronary CT angiography or angiography to exclude epicardial coronary artery disease

4. Investigate to detect venous and/or pulmonary thromboembolism (particulary in the presence of sepsis) 5. In the presence of elevation of IL-6, consider additional therapy targeted at cytokine release syndrome (in particular IL-6 receptor blocker)

6. Anticipate the potential need to mechanical circulatory support with all the relevant considerations $98-100$

Fig. 8 Triage risk stratification tool for high-risk patients with COVID-19 and cardiovascular disease 


\section{Conclusion}

This study showed that pre-existing and newly developed cardiovascular disease are common in patients with COVID-19 and are associated with increased severity and mortality in these patients. The frequency, clinical pattern, severity, and outcome of cardiovascular injury in pediatric patients with COVID-19 is not only different from the adult population but also varies in the pediatric age range, ranging from no cardiac damage in the majority of cases to Kawasaki Shock-like syndrome in the minority. We proposed a triage risk stratification tool in patients with COVID-19 and CVD for timely recognition of the high-risk patients and well-timed establishment of the pathophysiologically targeted treatment. This tool needs to be validated in future studies.

Lastly, COVID-19 should be regarded as a disease that can affect multiple organs with multiple mechanisms, each of which may need therapy targeted at the mechanism of injury in order to be effective.

\section{Limitations}

There were significant inconsistencies in reporting cardiovascular derangements in patients with COVID-19. Consistent terminology and definition of cardiac injury were not used in the studies. Furthermore, the $I^{2}$ index was high in some meta-analyses. Certain studies had done intensive evaluation and had presented immense information, whereas there was a dearth of information regarding the patients in others. These limitations indicate the necessity of a standardized terminology to report cardiovascular complications and a standard diagnostic approach to patients with COVID-19 worldwide. We did not include cardiac arrest in our analysis because the precise underlying pathophysiology of dying process (end-stage respiratory failure, cardiogenic shock, multiple organ failure, or cardiogenic shock) was not delineated in the majority of studies [112]. We could not include obesity in our study because data in this regard was not provided in the majority of studies. Another limitation of this study was that we did not search Cochrane, CINAHL, Web of Science, Scopus, and Google Scholar database in our online search [113]. Lastly, the limitations due to the possible inherent biases in the non-randomized cohort data apply to this study.

\section{Supplementary information}

Supplementary information accompanies this paper at https://doi.org/10. 1186/s43044-020-00075-z.

Additional file 1: Supplementary Material 1 (S1) Search strategy

Additional file 2: Supplementary Material 2 (S2) Supplementary

Table 1. Summary of the 35 studies included in the meta-analysis

Additional file 3: Supplementary Material 3 (S3) Supplementary Table2. Inflammatory and cardiac biomarkers in COVID-19
Additional file 4: Supplementary Material 4 (S4) Risk of bias assessment

Additional file 5: Supplementary Material 5 (S5) Figure 1. Forest plot of the pooled frequency analyses (including Figure 1. Forest plot of the pooled frequency analysis of newly developed acute cardiac injury. Figure 2. Forest plot of the pooled frequency analysis of newly developed arrhythmia. Figure 3. Forest plot of the pooled frequency analysis of newly developed heart failure. Figure 4. Forest plot of the pooled frequency analysis of chest pain or chest tightness. Figure $\mathbf{5}$. Forest plot of the pooled frequency analysis of palpitation. Figure $\mathbf{6}$. Forest plot of the pooled frequency analysis of hypertension. Figure $\mathbf{7 .}$ Forest plot of the pooled frequency analysis of pre-existing cardiovascular diseases. Figure 8. Forest plot of the pooled frequency analysis of preexisting heart failure. Figure 9. Forest plot of the pooled frequency analysis of pre-existing diabetes. Figure 10. Forest plot of the pooled frequency analysis of patients with elevated NT-pro BNP levels. Figure $\mathbf{1 1 .}$ Forest plot of the pooled frequency analysis of patients with elevated cardiac troponins levels. Figure 12. Forest plot of the pooled frequency analysis of patients with elevated creatine kinase-MB levels. Figure 13. Forest plot of the pooled frequency analysis of patients with elevated creatine kinase levels. Figure 14. Forest plot of the pooled frequency analysis of patients with elevated D-dimer levels. Figure 15. Forest plot of the pooled frequency analysis of patients with elevated lactate dehydrogenase levels. Figure 16. Forest plot of the pooled frequency analysis of patients with elevated interleukin- 6 levels. Figure 17. Forest plot of the pooled frequency analysis of patients with elevated C-Reactive Protein (CRP) levels. Figure 18. Forest plot of the pooled frequency analysis of patients with elevated erythrocyte sedimentation rate (ESR) levels. Figure 19. Forest plot of the pooled frequency analysis of patients with elevated ferritin levels).

Additional file 6: Forest plots showing odds ratio for death according to newly developed acute cardiac injury, pre-existing cardiovascular disease, hypertension and diabetes mellitus.

Additional file 7: Supplementary Material 7 (S7) Figure 1. Funnel plot of studies comparing frequency of acute cardiac injury between severe or ICU group and non-severe or non-ICU group showing publication bias. Figure 2. Funnel plot of studies comparing frequency of preexisting cardiovascular diseases between severe or ICU group and nonsever or non-ICU group showing publication bias. Figure 3. Funnel plot of studies comparing frequency of pre-existing cardiovascular disease between severe or ICU group and non-severe or non-ICU group showing publication bias. Figure 4. Funnel plot of studies comparing frequency of acute cardiac injury between deceased and survived patients showing publication bias

Additional file 8: Supplementary Material 8 (S8) Supplementary Table 3-Cardiac pathologic findings in 13 deceased patients with COVID-19. A: absent, CAA: coronary artery atherosclerosis, CAD: coronary artery disease, ECG: electrocardiography, EM: electron microscopy, hs-cTn: highsensitivity cardiac troponin I, LVEF: left ventricular ejection fraction, NS: not stated, P: present

\section{Abbreviations}

ACE2: Angiotensin-converting enzyme 2; AVB: Atrioventricular block; CAC: COVID-19-associated coagulopathy; CBC: Complete blood count; $\mathrm{Cl}$ : Confidence interval; CK: Creatine kinase; CK-MB: Craetine-kinase-MB; COVID-19: Coronavirus disease 2019; CRP: C-reactive protein;

CVD: Cardiovascular disease; ECMO: Extracorporeal membrane oxygenation; ESR: Erythrocye sedimentation rate; IABP: Intraaortic balloon pump; ICU: Intensive care unit; IL-6: Interleukin-6; IQR: Interquartile range; LDH: Lactate dehydrogenase; NT-proBNP: N-terminal-pro B-type natriuretic peptide; OR: Odds ratio; PRISMA: Preferred Reporting Items for Systematic Reviews and Meta-Analyses; RAAS: Renin-angiotensin-aldosterone system; S: Supplementary; SD: Standard deviation; SMD: Standard mean difference; Tn: Troponin; TNF-a: Tumor necrosis factor-alpha; TRST: Triage risk stratification tool

\section{Acknowledgements}

We are grateful to physicians, nurses, and the entire staff who serve the COVID-19 patients across the world. 


\section{Authors' contributions}

SM co-developed the concept and design, collected the data, performed the statistical analysis, and had a major contribution in writing the manuscript. PS collected the data and had a major contribution in writing the manuscript. SH performed the statistical analysis. BD and HME critically revised the manuscript and had a major contribution in finalizing the manuscript. EMR conceived the original idea, collected the data, had a major contribution in writing the manuscript, and supervised the project. All authors contributed to the final manuscript, read, and approved the final manuscript.

\section{Funding}

No funding was received for this study.

\section{Availability of data and materials}

Data is available on request.

\section{Ethics approval and consent to participate}

This study was a review of the literature and obtaining the approval of the ethics committee was not applicable. Consent to participate is not applicable.

\section{Consent for publication}

Not applicable.

\section{Competing interests}

The authors have no competing interest to declare.

\section{Author details}

${ }^{1}$ Tehran University of Medical Sciences, Tehran, Iran. ${ }^{2}$ Scientific Education and Research Network (USERN), Tehran, Iran. ${ }^{3}$ Research Center for Immunodeficiencies, Tehran University of Medical Sciences, Tehran, Iran. ${ }^{4}$ Cardiology Department, Queen Elizabeth Hospital, University Hospitals Birmingham NHS Foundation Trust, Birmingham, UK. ${ }^{5} \mathrm{Glenmark}$ Cardiac Centre, Mumbai, India. ${ }^{6}$ Department of Pediatric Cardiology, Children's Medical Center (Pediatric Center of Excellence), Tehran University of Medical Sciences, Tehran, Iran.

Received: 22 May 2020 Accepted: 2 July 2020

Published online: 13 July 2020

\section{References}

1. World Health Organization, Coronavirus disease (COVID-19) Situation Report - 115, Data as received by WHO from national authorities by 10:00 CEST, 14 May 2020. Vol 2020.

2. Lai CC, Liu YH, Wang CY, et al. Asymptomatic carrier state, acute respiratory disease, and pneumonia due to severe acute respiratory syndrome coronavirus 2 (SARS-CoV-2): Facts and myths. J Microbiol Immunol Infect. 2020.

3. Arentz M, Yim E, Klaff $L$, et al. Characteristics and Outcomes of 21 Critically III Patients With COVID-19 in Washington State. JAMA. 2020.

4. Wan S, Xiang Y, Fang W et al (2020) Clinical features and treatment of COVID-19 patients in northeast Chongqing. J Med Virol.

5. Zheng Y-Y, Ma Y-T, Zhang J-Y, Xie X (2020) COVID-19 and the cardiovascular system. Nature Reviews Cardiology. 17:259-260

6. Li JW, Han TW, Woodward M et al (2020) The impact of 2019 novel coronavirus on heart injury: a systemic review and Meta-analysis. Prog Cardiovasc Dis.

7. Fox SE, Akmatbekov A, Harbert JL, Li G, Brown JQ, Vander Heide RS. Pulmonary and cardiac pathology in Covid-19: the first autopsy series from New Orleans. medRxiv. 2020:2020.2004.2006.20050575.

8. Wells GA, Tugwell P, O'Connell D, et al. The Newcastle-Ottawa Scale (NOS) for assessing the quality of nonrandomized studies in meta-analyses. 2015.

9. OpenMetaAnalyst: Wallace BC, Issa J. Dahabreh, Thomas A. Trikalinos, Joseph Lau, Paul Trow, and Christopher H. Schmid. "Closing the Gap between Methodologists and End-Users: R as a Computational Back-End." Journal of Statistical Software 2012;49:5.

10. Review Manager (RevMan). 5.3 ed. Copenhagen: The Nordic Cochrane Centre: The Cochrane Collaboration; 2014

11. Huedo-Medina TB, Sanchez-Meca J, Marin-Martinez F, Botella J (2006) Assessing heterogeneity in meta-analysis: Q statistic or 12 index? Psychol Methods. 11:193-206
12. Barili F, Parolari A, Kappetein PA, Freemantle N (2018) Statistical Primer: heterogeneity, random- or fixed-effects model analyses? Interact Cardiovasc Thorac Surg. 27:317-321

13. Luo D, Wan X, Liu J, Tong T (2016) Optimally estimating the sample mean from the sample size, median, mid-range, and/or mid-quartile range. Stat Methods Med Res. 27:1785-1805

14. Wan $X$, Wang W, Liu J, Tong $T$ (2014) Estimating the sample mean and standard deviation from the sample size, median, range and/or interquartile range. BMC Med Res Methodol. 14:135

15. Du RH, Liu LM, Yin W, et al. Hospitalization and critical care of 109 decedents with COVID-19 pneumonia in Wuhan, China. Ann Am Thorac Soc. 2020.

16. Wan S, Xiang Y, Fang W, et al. Clinical features and treatment of COVID-19 patients in northeast Chongqing. Journal of Medical Virology. 2020;n/a.

17. Chen C, Chen C, Yan JT, Zhou N, Zhao JP, Wang DW (2020) Analysis of myocardial injury in patients with COVID-19 and association between concomitant cardiovascular diseases and severity of COVID-19. Zhonghua Xin Xue Guan Bing Za Zhi 48:E008

18. Chen N, Zhou M, Dong X et al (2020) Epidemiological and clinical characteristics of 99 cases of 2019 novel coronavirus pneumonia in Wuhan, China: a descriptive study. The Lancet. 395:507-513

19. Chen T, Wu D, Chen H et al (2020) Clinical characteristics of 113 deceased patients with coronavirus disease 2019: retrospective study. BMJ. 368:m1091

20. Deng Y, Liu W, Liu K, et al. Clinical characteristics of fatal and recovered cases of coronavirus disease 2019 (COVID-19) in Wuhan, China: a retrospective study. Chin Med J (Engl). 2020.

21. Deng Y, Liu W, Liu K, et al. Clinical characteristics of fatal and recovered cases of coronavirus disease 2019 (COVID-19) in Wuhan, China: a retrospective study. Chinese Medical Journal. 9000;Publish Ahead of Print.

22. Du RH, Liang $L R$, Yang $C Q$, et al. Predictors of mortality for patients with COVID-19 pneumonia caused by SARS-CoV-2: a prospective cohort study. Eur Respir J. 2020

23. Du Y, Tu L, Zhu P, et al. Clinical Features of 85 Fatal Cases of COVID-19 from Wuhan: a retrospective observational study. American Journal of Respiratory and Critical Care Medicine. 2020.

24. Gao L, Jiang D, Wen X-S, et al. Prognostic value of NT-proBNP in patients with severe COVID-19. Respiratory Research. 2020;21:83.

25. Garg S KL, Whitaker M, et al. Hospitalization rates and characteristics of patients hospitalized with laboratory-confirmed coronavirus disease 2019-COVID-NET, 14 States, March 1-30, 2020. MMWR Morb Mortal Wkly Rep 2020;69:458-464.

26. Grasselli G, Zangrillo A, Zanella A, et al. Baseline characteristics and outcomes of 1591 patients infected with SARS-CoV-2 admitted to ICUs of the Lombardy Region, Italy. JAMA. 2020.

27. Guo T, Fan Y, Chen M, et al. Cardiovascular Implications of Fatal Outcomes of Patients With Coronavirus Disease 2019 (COVID-19). JAMA Cardiology. 2020.

28. Han $\mathrm{H}$, Xie L, Liu R, et al. Analysis of heart injury laboratory parameters in 273 COVID-19 patients in one hospital in Wuhan, China. Journal of Medical Virology. 2020;n/a.

29. He XW, Lai JS, Cheng J, et al. [Impact of complicated myocardial injury on the clinical outcome of severe or critically ill COVID-19 patients]. Zhonghua Xin Xue Guan Bing Za Zhi. 2020;48:E011.

30. Huang C, Wang Y, Li X et al (Lancet, 2020) Clinical features of patients infected with 2019 novel coronavirus in Wuhan, China. 395:497-506

31. Lei S, Jiang F, Su W et al (2020) Clinical characteristics and outcomes of patients undergoing surgeries during the incubation period of COVID-19 infection. EClinicalMedicine. 100331

32. Li R, Tian J, Yang F et al (2020) Clinical characteristics of 225 patients with COVID-19 in a tertiary Hospital near Wuhan, China. J Clin Virol 127:104363

33. Li X, Xu S, Yu M, et al. Risk factors for severity and mortality in adult COVID19 inpatients in Wuhan. J Allergy Clin Immunol. 2020.

34. Lian J, Jin X, Hao S, et al. Analysis of epidemiological and clinical features in older patients with Corona Virus Disease 2019 (COVID-19) out of Wuhan. Clinical Infectious Diseases. 2020.

35. Liu K, Fang YY, Deng Y, et al. Clinical characteristics of novel coronavirus cases in tertiary hospitals in Hubei Province. Chin Med J (Engl). 2020;133(9): 1025-31. https://doi.org/10.1097/CM9.0000000000000744.

36. Peng YD, Meng K, Guan HQ et al (2020) Clinical characteristics and outcomes of 112 cardiovascular disease patients infected by 2019-nCoV. Zhonghua Xin Xue Guan Bing Za Zhi 48:E004 
37. Ruan Q, Yang K, Wang W, Jiang L, Song J (2020) Clinical predictors of mortality due to COVID-19 based on an analysis of data of 150 patients from Wuhan. China, Intensive Care Med

38. Shi S, Qin M, Shen B et al (2020) Association of Cardiac Injury With Mortality in Hospitalized Patients With COVID-19 in Wuhan. China, JAMA Cardiology

39. Sun C, Zhang XB, Dai Y, Xu XZ, Zhao J (2020) Clinical analysis of 150 cases of 2019 novel coronavirus infection in Nanyang City, Henan Province. Zhonghua Jie He He Hu Xi Za Zhi 43:E042

40. Wang D, Hu B, Hu C et al (2020) Clinical characteristics of 138 hospitalized patients with 2019 novel coronavirus-infected pneumonia in Wuhan, China. JAMA 323:1061-1069

41. Xu X, Yu C, Qu J et al (2020) Imaging and clinical features of patients with 2019 novel coronavirus SARS-CoV-2. Eur J Nucl Med Mol Imaging. 47:1275-1280

42. Xu X-W, Wu X-X, Jiang X-G et al (2020) Clinical findings in a group of patients infected with the 2019 novel coronavirus (SARS-Cov-2) outside of Wuhan, China: retrospective case series. BMJ 368:m606

43. Young BE, Ong SWX, Kalimuddin S, et al. Epidemiologic features and clinical course of patients infected with SARS-CoV-2 in Singapore. JAMA. 2020.

44. Zhang J-J, Dong X, Cao Y-Y, et al. Clinical characteristics of 140 patients infected with SARS-CoV-2 in Wuhan, China. Allergy. 2020;n/a.

45. Zhang $P$, Zhu L, Cai J, et al. Association of inpatient use of angiotensin converting enzyme inhibitors and angiotensin II receptor blockers with mortality among patients with hypertension hospitalized With COVID-19. Circ Res. 2020

46. Zheng F, Tang W, Li H, Huang YX, Xie YL, Zhou ZG (2020) Clinical characteristics of 161 cases of corona virus disease 2019 (COVID-19) in Changsha. Eur Rev Med Pharmacol Sci. 24:3404-3410

47. Zhou F, Yu T, Du R et al (2020) Clinical course and risk factors for mortality of adult inpatients with COVID-19 in Wuhan, China: a retrospective cohort study. Lancet. 395:1054-1062

48. Xanthopoulos A, Starling RC, Kitai T, Triposkiadis F (2019) Heart failure and liver disease: cardiohepatic interactions. JACC Heart Fail. 7:87-97

49. Samsky MD, Patel CB, DeWald TA et al (2013) Cardiohepatic interactions in heart failure: an overview and clinical implications. J Am Coll Cardiol. 61: 2397-2405

50. Tabucanon T, Tang WHW (2020) Right Heart Failure and Cardiorenal Syndrome. Cardiol Clin. 38:185-202

51. Raina R, Nair N, Chakraborty R, Nemer L, Dasgupta R, Varian K (2020) An Update on the pathophysiology and treatment of cardiorenal syndrome. Cardiol Res. 11:76-88

52. Savira F, Magaye R, Liew D, et al. Cardiorenal syndrome: multi-organ dysfunction involving the heart, kidney and vasculature. Br J Pharmacol. 2020

53. Sala S, Peretto G, Gramegna M, et al. Acute myocarditis presenting as a reverse Tako-Tsubo syndrome in a patient with SARS-CoV-2 respiratory infection. European Heart Journal. 2020.

54. Irabien-Ortiz A. [Fulminant myocarditis due to COVID-19]. Rev Esp Cardiol. 2020.

55. Hu H, Ma F, Wei X, Fang Y. Coronavirus fulminant myocarditis treated with glucocorticoid and human immunoglobulin. European Heart Journal. 2020.

56. Zeng JH, Liu YX, Yuan J, et al. First case of COVID-19 complicated with fulminant myocarditis: a case report and insights. Infection. 2020.

57. Leonard-Lorant I, Delabranche X, Severac F, et al. Acute pulmonary embolism in COVID-19 patients on CT angiography and relationship to Ddimer levels. Radiology. 2020:201561.

58. Casey K, Iteen A, Nicolini R, Auten J (2020) COVID-19 pneumonia with hemoptysis: acute segmental pulmonary emboli associated with novel coronavirus infection. Am J Emerg Med.

59. Fabre O, Rebet O, Carjaliu I, Radutoiu M, Gautier L, Hysi I (2020) Severe Acute Proximal Pulmonary Embolism and COVID-19: A Word of Caution. Ann Thorac Surg.

60. Cellina M, Oliva G. Acute pulmonary embolism in a patient with COVID-19 pneumonia. Diagn Interv Imaging. 2020.

61. Tavazzi G, Pellegrini C, Maurelli M, et al. Myocardial localization of coronavirus in COVID-19 cardiogenic shock. Eur J Heart Fail. 2020.

62. Fried JA, Ramasubbu K, Bhatt $R$, et al. The variety of cardiovascular presentations of COVID-19. Circulation. 2020.

63. Juusela A, Nazir M, Gimovsky M. Two cases of coronavirus 2019-related cardiomyopathy in pregnancy. Am J Obstetr Gynecol MFM. 2020:100113.

64. Sala S, Peretto G, Gramegna M, et al. Acute myocarditis presenting as a reverse Tako-Tsubo syndrome in a patient with SARS-CoV-2 respiratory infection. Eur Heart J. 2020.
65. Ullah W, Saeed R, Sarwar U, Patel R, Fischman DL. COVID-19 complicated by acute pulmonary embolism and right-sided heart failure. JACC Case Rep. 2020.

66. Danzi GB, Loffi M, Galeazzi G, Gherbesi E. Acute pulmonary embolism and COVID-19 pneumonia: a random association? Eur Heart J. 2020.

67. Cui Y, Tian M, Huang D, et al. A 55-Day-Old Female Infant infected with COVID 19: presenting with pneumonia, liver injury, and heart damage. J Infect Dis. 2020.

68. Jones VG, Mills M, Suarez D, et al. COVID-19 and Kawasaki disease: novel virus and novel case. Hosp Pediatr. 2020.

69. Riphagen S, Gomez X, Gonzalez-Martinez C, Wilkinson N, Theocharis P. Hyperinflammatory shock in children during COVID-19 pandemic. Lancet. 2020

70. Libby P (2020) The Heart in COVID19: Primary Target or Secondary Bystander? JACC Basic Transl Sci

71. Tan W, Aboulhosn J. The cardiovascular burden of coronavirus disease 2019 (COVID-19) with a focus on congenital heart disease. Int J Cardiol. 2020.

72. Mehra MR, Ruschitzka F. COVID-19 illness and heart failure: a missing link? JACC: Heart Failure. 2020:1248

73. Clerkin KJ, Fried JA, Raikhelkar J, et al. Coronavirus disease 2019 (COVID-19) and cardiovascular disease. Circulation. 2020.

74. Roden DM, Harrington RA, Poppas A, Russo AM. Considerations for drug interactions on QTc in exploratory COVID-19 (Coronavirus Disease 2019) Treatment. Heart Rhythm. 2020.

75. He J, Wu B, Chen Y, et al. Characteristic Electrocardiographic Manifestations in Patients With COVID-19. Can J Cardiol. 2020.

76. Tian S, Xiong Y, Liu H, et al. Pathological study of the 2019 novel coronavirus disease (COVID-19) through postmortem core biopsies. Modern Pathology. 2020

77. Barton LM, Duval EJ, Stroberg E, Ghosh S, Mukhopadhyay S. COVID-19 Autopsies, Oklahoma, USA. Am J Clin Pathol. 2020.

78. Xu Z, Shi L, Wang Y et al (2020) Pathological findings of COVID-19 associated with acute respiratory distress syndrome. Lancet Respir Med. 8: 420-422

79. Yao XH, Li TY, He ZC et al (2020) A pathological report of three COVID-19 cases by minimally invasive autopsies. Zhonghua Bing Li Xue Za Zhi 49:E009

80. Robles NR, Macias JF (2015) Hypertension in the elderly. Cardiovasc Hematol Agents Med Chem. 12:136-145

81. Onder G, Rezza G, Brusaferro S. Case-fatality rate and characteristics of patients dying in relation to COVID-19 in Italy. JAMA. 2020.

82. Buford TW (2016) Hypertension and aging. Ageing Res Rev. 26:96-111

83. Santoso A, Pranata R, Wibowo A, Al-Farabi MJ, Huang I, Antariksa B. Cardiac injury is associated with mortality and critically ill pneumonia in COVID-19: A meta-analysis. Am J Emerg Med. 2020.

84. Nelson T, Garg P, Clayton RH, Lee J (2019) The Role of Cardiac MRI in the Management of ventricular arrhythmias in ischaemic and non-ischaemic dilated cardiomyopathy. Arrhythm Electrophysiol Rev. 8:191-201

85. Huber SA (2016) Viral myocarditis and dilated cardiomyopathy: etiology and pathogenesis. Curr Pharm Des. 22:408-426

86. Dabir D, Vollbrecht TM, Luetkens JA et al (2019) Multiparametric cardiovascular magnetic resonance imaging in acute myocarditis: a comparison of different measurement approaches. J Cardiovasc Magn Reson. 21:54

87. Becker RC. COVID-19 update: Covid-19-associated coagulopathy. J Thromb Thrombol. 2020.

88. Fogarty H, Townsend L, Ni Cheallaigh C, et al. COVID19 coagulopathy in Caucasian patients. Br J Haematol. 2020

89. Thachil J, Agarwal S. Understanding the COVID-19 coagulopathy spectrum. Anaesthesia. 2020.

90. Gomez-Arbelaez D, Ibarra-Sanchez G, Garcia-Gutierrez A, Comanges-Yeboles A, Ansuategui-Vicente M, Gonzalez-Fajardo JA. Covid-19-related aortic thrombosis: a report of four cases. Ann Vasc Surg. 2020.

91. Tang N, Li D, Wang X, Sun Z (2020) Abnormal coagulation parameters are associated with poor prognosis in patients with novel coronavirus pneumonia. J Thromb Haemost. 18:844-847

92. Thachil J, Tang N, Gando S et al (2020) ISTH interim guidance on recognition and management of coagulopathy in COVID-19. J Thromb Haemost. 18:1023-1026

93. Bikdeli B, Madhavan MV, Jimenez D et al (2020) COVID-19 and thrombotic or thromboembolic disease: implications for prevention, antithrombotic therapy, and follow-up. J Am Coll Cardiol. 
94. Tang N, Bai H, Chen X, Gong J, Li D, Sun Z (2020) Anticoagulant treatment is associated with decreased mortality in severe coronavirus disease 2019 patients with coagulopathy. J Thromb Haemost. 18:1094-1099

95. Coomes EA, Haghbayan H. Interleukin-6 in COVID-19: a systematic review and meta-analysis. medRxiv. 2020:2020.2003.2030.20048058.

96. Zhang C, Wu Z, Li JW, Zhao H, Wang GQ (2020) The cytokine release syndrome (CRS) of severe COVID-19 and Interleukin-6 receptor (IL-6R) antagonist Tocilizumab may be the key to reduce the mortality. Int J Antimicrob Agents. 105954

97. Zhu ZW, Tang JJ, Chai XP et al (2020) Comparison of heart failure and 2019 novel coronavirus pneumonia in chest $C T$ features and clinical characteristics. Zhonghua Xin Xue Guan Bing Za Zhi 48:E007

98. Guo T, Fan Y, Chen M, et al. Cardiovascular implications of fatal outcomes of patients with coronavirus disease 2019 (COVID-19). JAMA Cardiol. 2020.

99. Ciu H, Wu J, Hong L, Luo Y, Song Q, Chen D. Clinical and epidemiological features of 36 children with coronavirus disease 2019 (COVID-19) in Zhejiang, China: an observational cohort study. Lancet Infect Dis. 2020

100. Dong Y, Mo X, Hu Y, et al. Epidemiological characteristics of 2143 pediatric patients with 2019 coronavirus disease in China. Pediatrics. 2020:e20200702.

101. Ludvigsson JF. Systematic review of COVID-19 in children shows milder cases and a better prognosis than adults. Acta Paediatr. 2020.

102. Shekerdemian LS, Mahmood NR, Wolfe KK, et al. Characteristics and outcomes of children With Coronavirus Disease 2019 (COVD-19) Infection Admitted to US and Canadian Pediatric Intensive Care Units. JAMA Pediatr. 2020.

103. Brojakowska A, Narula J, Shimony R, Bander J. Clinical Implications of SARSCov2 interaction with renin angiotensin system. J Am Coll Cardiol. 2020

104. Liu K, Chen Y, Lin R, Han K. Clinical features of COVID-19 in elderly patients: a comparison with young and middle-aged patients. J Infect. 2020.

105. Etard JF, Vanhems P, Atlani-Duault L, Ecochard R. Potential lethal outbreak of coronavirus disease (COVID-19) among the elderly in retirement homes and long-term facilities, France, March 2020. Euro Surveill. 2020;25.

106. Andersen K (2009) Renin-angiotensin-aldosterone system in the elderly: rational use of aliskiren in managing hypertension. Clin Interv Aging. 4:137-151

107. Musso CG, Jauregui JR (2014) Renin-angiotensin-aldosterone system and the aging kidney. Exp Rev Endocrinol Metabol 9:543-546

108. Busse PJ, Mathur SK (2010) Age-related changes in immune function: effect on airway inflammation. J Allergy Clin Immunol. 126:690-699 quiz 700-691

109. Khan R, Anandamurthy B, McCurry K, Krishnan S. Utility of extracorporeal membrane oxygenation in COVID-19. Cleve Clin J Med. 2020.

110. Kusne S, Staley L, Arabia F (2017) Prevention and infection management in mechanical circulatory support device recipients. Clin Infect Dis. 64:222-228

111. Chow J, Alhussaini A, Calvillo-Arguelles O, Billia F, Luk A. Cardiovascular collapse in COVID-19 infection: the role of veno-arterial extracorporeal membrane oxygenation (VA-ECMO). CJC Open. 2020.

112. Vincent IL, Taccone FS (2020) Understanding pathways to death in patients with COVID-19. Lancet Respir Med. 8:430-432

113. Bramer WM, Rethlefsen ML, Kleijnen J, Franco OH (2017) Optimal database combinations for literature searches in systematic reviews: a prospective exploratory study. Syst Rev. 6:245

\section{Publisher's Note}

Springer Nature remains neutral with regard to jurisdictional claims in published maps and institutional affiliations.

\section{Submit your manuscript to a SpringerOpen ${ }^{\circ}$ journal and benefit from:}

- Convenient online submission

- Rigorous peer review

- Open access: articles freely available online

- High visibility within the field

- Retaining the copyright to your article

Submit your next manuscript at $\boldsymbol{\nabla}$ springeropen.com 